Marquette University

e-Publications@Marquette

$7-2004$

\title{
Understanding Adolescent Intentions to Smoke: An Examination of Relationships Among Social Influence, Prior Trial Behavior, and Antitobacco Campaign Advertising
}

\author{
J. Craig Andrews \\ Marquette University, craig.andrews@marquette.edu \\ Richard G. Netemeyer \\ University of Virginia - Main Campus \\ Scot Burton \\ University of Arkansas - Main Campus \\ David Paul Moberg \\ Marquette University \\ Ann Christiansen \\ University of Wisconsin
}

Follow this and additional works at: https://epublications.marquette.edu/market_fac

Part of the Marketing Commons

Recommended Citation

Andrews, J. Craig; Netemeyer, Richard G.; Burton, Scot; Moberg, David Paul; and Christiansen, Ann, "Understanding Adolescent Intentions to Smoke: An Examination of Relationships Among Social Influence, Prior Trial Behavior, and Antitobacco Campaign Advertising" (2004). Marketing Faculty Research and Publications. 63.

https://epublications.marquette.edu/market_fac/63 


\section{J. Craig Andrews, Richard G. Netemeyer, Scot Burton, D. Paul Moberg, \& Ann Christiansen}

\section{Understanding Adolescent Intentions to Smoke: An Examination of Relationships Among Social Influence, Prior Trial Behavior, and Antitobacco Campaign Advertising}

Telephone interviews were conducted with more than 900 adolescents aged 12 to 18 as part of a multimillion dollar, statewide, antitobacco advertising campaign. The interviews addressed two primary questions: (1) Do counteradvertising campaign attitudes directly affect antismoking beliefs and intent in a manner similar to those of conventional advertisements? and (2) Can advertising campaign attitudes have a stronger effect on beliefs and intent for adolescents with prior smoking behavior and for adolescents exposed to social influence (i.e., friends, siblings, or adult smoker in the home)? The authors' findings show that advertising campaign attitudes, prior trial behavior, and social influence all directly affect antismoking beliefs and that advertising campaign attitudes interact with prior trial behavior to strengthen antismoking beliefs. The results indicate that attitudes related to the campaign, prior trial behavior, and social influence directly influence intent, and advertising campaign attitudes interact with social influence and prior trial behavior to attenuate adolescent intent to smoke. In addition, the effect of advertising campaign attitudes in attenuating social influence and prior trial behavior effects on adolescent intent to smoke persists even when the authors account for strongly held beliefs about smoking. The authors discuss implications for countermarketing communications and the design and understanding of future antismoking campaigns.

A $\mathrm{n}$ understanding of why adolescents decide to smoke and the development of successful countermeasures are important issues in the public health and social marketing fields today. The statistics on smoking morbidity are compelling. For example, tobacco use is the leading preventable cause of death in the United States, contributing to more than 440,000 deaths each year and resulting in \$75 billion in direct medical costs (Centers for Disease Control and Prevention [CDC] 2002). Furthermore, the U.S. Food and Drug Administration has characterized smoking as a

J. Craig Andrews is Professor and Charles H. Kellstadt Chair in Marketing, College of Business Administration, Marquette University (e-mail: craig.andrews@marquette.edu). Richard G. Netemeyer is Professor of Commerce, Mclntire School of Commerce, University of Virginia (e-mail: rgn3p@forbes2.comm.virginia.edu). Scot Burton is Professor and WalMart Chairholder in Marketing, Sam M. Walton College of Business, University of Arkansas (e-mail: sburton@ walton.uark.edu). D. Paul Moberg is Director, Center for Health Policy \& Program Evaluation, and Senior Scientist, Department of Population Health Sciences, University of Wisconsin Medical School (e-mail: dpmoberg @ wisc.edu). Ann Christiansen is Associate Researcher, Comprehensive Cancer Center, University of Wisconsin (e-mail: christia@uwccc.wisc.edu). The authors gratefully acknowledge the helpful comments from Joel Cohen, Connie Pechmann, Terry Shimp, and the anonymous $J M$ reviewers on a previous version of this article. They also appreciate the help of the Wisconsin Tobacco Control Board, BVK-McDonald, Market Strategies, David Ahrens, and Amanda Riemer in the data collection process. pediatric disease; $80 \%$ of current adult smokers began before age 18, and more than 5000 youths try their first cigarette each day (CDC 2002). Adolescents are estimated to have three times the sensitivity to cigarette advertising than adults (Pollay et al. 1996), and recent documents have shown youths to be an important target market for the tobacco industry (Cohen 2000; Pollay and Lavack 1993).

What, then, leads adolescents to smoke? Demographic analyses suggest that there is a greater tendency for older, Caucasian, male youths who are not in school to smoke than there is for other adolescent groups (Jamieson and Romer 2001). Other potential predictors of adolescent smoking include social influence (e.g., friends or family effects), prior smoking behavior, and imagery portrayed in tobacco advertising (Aloise-Young, Graham, and Hansen 1994; Pechmann and Knight 2002). For example, tobacco advertising has been shown to have both direct and indirect effects on adolescent smoking behavior. Cohen (2000) suggests that tobacco advertising conveys symbolic and/or physiological benefits to adolescents that directly affect their decision to smoke. Alternatively, Romer and Jamieson (2001) present models that show that cigarette advertising encourages adolescents' attraction to peers who smoke and that peers' approval of smoking helps initiate smoking trial in peer groups (an indirect effect). Romer and Jamieson also find that cigarette advertising directly influences peer approval separate from its impact on imagery and feelings 
about smoking. In summary, evidence suggests that social influence and tobacco advertising can affect the decision to begin smoking.

In principle, Romer and Jamieson (2001) argue that antitobacco advertising may operate in a similar and opposite manner of tobacco advertising. That is, antitobacco advertisements are likely to counteract the approval and attraction process through the use of negative images of smokers and favorable images of nonsmokers. Thus, the models of Romer and Jamieson (2001) may be applicable to the study of social influence and antismoking ad campaigns. Given that state antitobacco programs have shown that counteradvertising can reduce the positive perceptions of smoking in peer networks and overall views of cigarette advertising (cf. Siegel and Biener 2000), antismoking advertisements may negatively affect intent to smoke. Still, how antismoking ad campaigns interact with social influence (and with other variables) has largely been unexplained, and the potential mediating role that beliefs about smoking may have in affecting intent to smoke has not been explored. Furthermore, it has been suggested that knowledge of teen smoking can be advanced by field studies that examine the combined effects of social influence, beliefs, and counteradvertising campaigns (Romer and Jamieson 2001). As such, our study addresses two primary questions: (1) Do counteradvertising campaign attitudes directly affect antismoking beliefs and intent in a manner similar to that of conventional advertisements? and (2) Can ad campaign attitudes have a stronger effect on beliefs and intent for adolescents with prior smoking behavior and for adolescents exposed to social influence (i.e., friends, siblings, or adult smoker in the home)? We use data from a major state antitobacco campaign to address these questions.

\section{Overview and Hypotheses Campaign Overview}

Our study examines predicted relationships that are tested in conjunction with Wisconsin's first major antitobacco advertising campaign, for which some $\$ 6.5$ million was allocated. Specific antismoking advertisements used in the campaign targeted youths of middle school and high school age, for whom smoking incidence rates were higher than national averages. The specific advertisements used had been successfully tested and run in other states, and the advertisements were placed in youth television and radio spots in seven major markets in the state running the antismoking campaign. A primary theme of the campaign was that of industry deception and anti-imagery, and other message themes focused on addiction and harmful effects of secondhand smoke. The campaign ran for approximately six months.

\section{Model Overview}

Figure 1 presents direct, interaction, and mediating relationships for two key dependent variables: antismoking beliefs about the campaign (beliefs) and intent to smoke. The interaction and mediating effects are of particular interest in contributing to the literature on countermarketing campaign advertising. We predict that prior smoking trial (prior trial behavior) as well as having siblings, an adult in the home, or friends who smoke (social influence) will negatively affect antismoking beliefs about the campaign (beliefs). A favorable attitude toward specific antitobacco campaign advertisements (ad campaign attitude) will have a positive effect on beliefs, and the negative effects of prior trial behavior and social influence on beliefs will be attenuated when they interact with ad campaign attitude. For intent to smoke, we predict that beliefs will have a negative effect, prior trial behavior and social influence positive effects, and ad campaign attitude a negative effect. In addition, we predict interactions such that the effects of prior trial behavior and social influence on intent to smoke will be attenuated by ad campaign attitude. Furthermore, we predict that beliefs will partially mediate the effects of social influence, ad campaign attitude, and the ad campaign attitude $\times$ social influence and ad campaign attitude $\times$ prior trial behavior interactions on intent to smoke. We subsequently discuss the rationale for these relationships.

\section{Predicted Effects on Beliefs}

Direct effects of prior trial behavior and social influence. Antismoking beliefs related to the campaign (beliefs) include that tobacco companies use deceptive practices in advertising, that smoking is addictive, and that secondhand smoke is harmful. We expect that prior trial behavior and social influence directly affect these beliefs for the following reasons. It has been shown that consumers ignore or counterargue messages that contradict their beliefs and behaviors (Petty and Cacioppo 1981), and research indicates that smokers tend to discount the negative consequences of smoking (Romer and Jamieson 2001). Such a process can occur even though the basis for such beliefs may be more emotional than has previously been believed (Slovic 2001). Thus, we expect that prior trial behavior negatively affects antismoking beliefs associated with the campaign.

We operationalize social influence as a behavioral construct that reflects the influence of family and peer smoking behavior on adolescents. The socialization process suggests that family and friends strongly influence the beliefs of adolescents (John 1999), and this effect is evident in the smoking literature. For example, Romer and Jamieson (2001) show that having friends or siblings who smoke weakens adolescents' beliefs about the risks of smoking, and Simons-Morten and colleagues (2001) suggest that parental guidance on not smoking lessens the positive beliefs that adolescents might have about smoking. Thus, we expect that social influence negatively affects antismoking beliefs (beliefs).

$\mathrm{H}_{1}$ : Antismoking beliefs (beliefs) are negatively affected by (a) trying cigarettes in the past (prior trial behavior) and (b) social influence (i.e., a sibling or friends who smoke, an adult smoker in the household).

Direct effects of ad campaign attitude. We expect that ad campaign attitude affects antismoking beliefs (beliefs) for several reasons. Hierarchy-of-effects models suggest a positive and direct relationship between attitude toward the ad and beliefs about the advertisement's message. For 


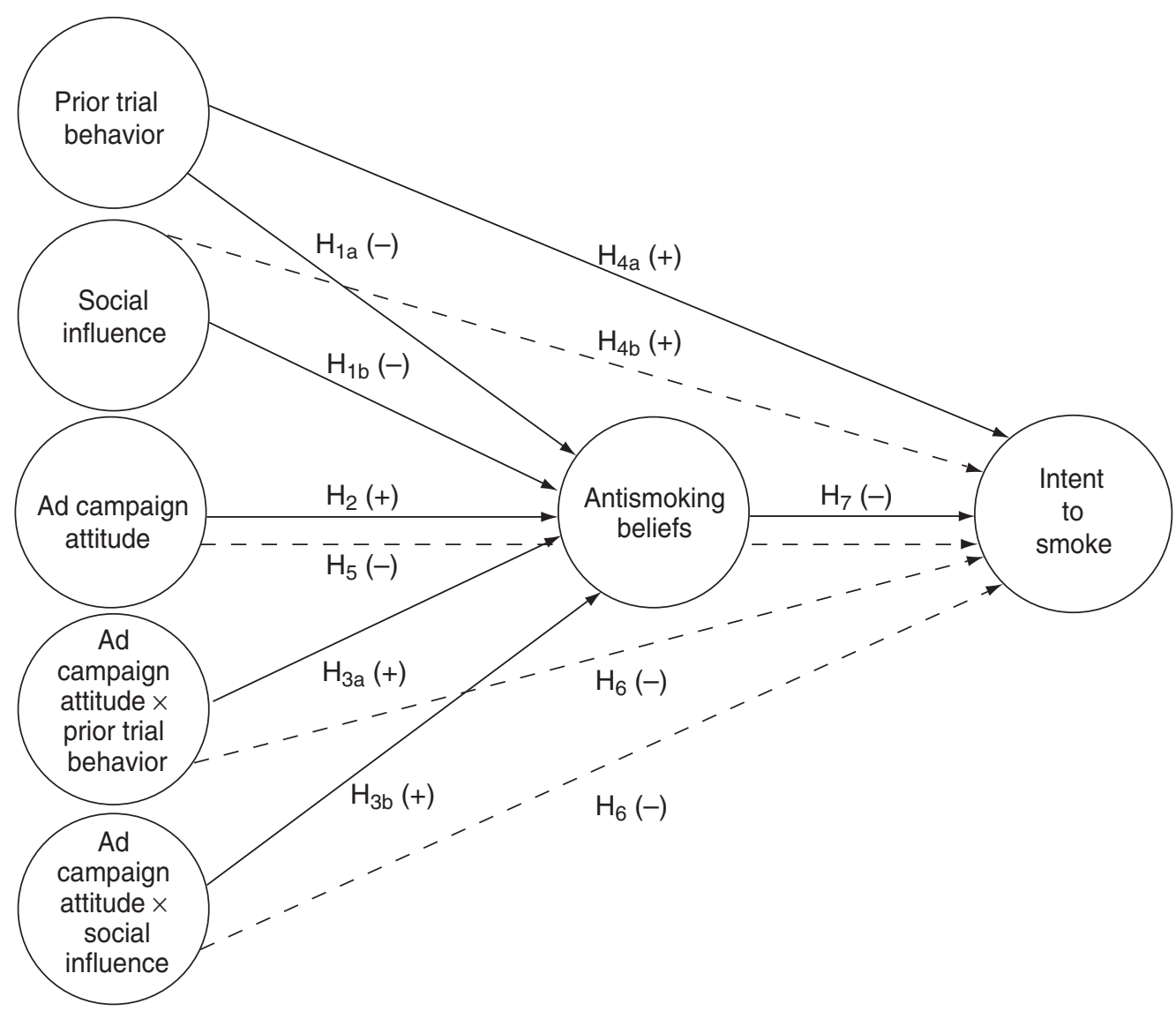

Notes: Lines with dashes indicate relationships hypothesized to be partially mediated by antismoking beliefs $\left(\mathrm{H}_{7}\right)$. The partially mediated effects include social influence $\rightarrow$ intent to smoke, ad campaign attitude $\rightarrow$ intent to smoke, ad campaign attitude $\times$ prior trial behavior $\rightarrow$ intent to smoke, and ad campaign attitude $\times$ social influence $\rightarrow$ intent to smoke. Ad campaign attitude $\times$ prior trial behavior and ad campaign attitude $\times$ social influence are hypothesized interactions.

example, Brown and Stayman (1992) report a link between attitude and consumer cognitions, and studies that involve dual-mode processes support a positive effect of attitude toward the ad on brand-related beliefs (Lutz 1985). Evidence from the diffusion model of smoking also suggests that with the creation of favorable imagery and affect, a subsequent decline in the negative risk beliefs about smoking follows (Romer and Jamieson 2001). If the diffusion model principle that antismoking advertisements can have the opposite effects holds, ad campaign attitude should positively and directly influence antismoking beliefs. Thus, ad campaign attitude should explain incremental variance in beliefs related to the campaign that prior trial behavior and social influence do not explain.

$\mathrm{H}_{2}$ : Favorable attitudes toward specific campaign advertisements (ad campaign attitude) positively affect antismoking beliefs (beliefs).

Interaction effects with ad campaign attitude. Although $\mathrm{H}_{1}$ and $\mathrm{H}_{2}$ are of interest to the smoking and advertising literature, they are direct-effects hypotheses. However, an understanding of the interactions among ad campaign attitude, prior trial behavior, and social influence may enhance knowledge of how these factors act in tandem to affect antismoking beliefs and intent to smoke. Although such interactions are consistent with conceptualizations that combine prior trial behavior with effects related to advertising (Vakratsas and Ambler 1999), we are not aware of any work that has addressed counteradvertising's interactions with prior trial behavior and social influence in their effects on adolescent antismoking beliefs.

We propose that ad campaign attitude serves to weaken the negative effects of prior trial behavior and social influence on antismoking beliefs. Antismoking beliefs are typical among youths (Barton et al. 1982; Chassin et al. 1981), but as we hypothesize, these beliefs can be weakened through direct experience with smoking or contact with peers who smoke (Pechmann and Knight 2002; Pechmann et al. 2003). Given such weaker antismoking beliefs, favorable campaign attitudes should have significant opportunity to affect beliefs. We expect this effect because there is greater room for change when prior antismoking beliefs are less robust. However, for adolescents with little smoking exposure, ad campaign attitude will have less opportunity to affect antismoking beliefs because they are already quite strong (for these adolescents, ad campaign attitude may 
tend to reinforce their existing antismoking beliefs). This rationale suggests that interactions of prior trial behavior and social influence with ad campaign attitude are positive and significant predictors of antismoking beliefs (beliefs). Specifically, we expect that ad campaign attitude has a stronger (and more positive) influence on antismoking beliefs for adolescents who have tried smoking or who have been exposed to social influence through friends or family.

$\mathrm{H}_{3}$ : The negative effects of (a) prior trial behavior and (b) social influence on antismoking beliefs (beliefs) are attenuated by favorable attitudes toward campaign advertisements (ad campaign attitude).

\section{Predicted Effects on Intent to Smoke}

Direct effects of prior trial behavior and social influence. As Bem (1967) suggests, attitudes and intent are often inferred from prior behavior. As applied to adolescent smoking, prior trial behavior (i.e., smoking trial in which at least one cigarette was partially smoked) should affect future behavior (and intent). Research suggests that when intent is measured for a specific context that involves observable and easily initiated behavior, it is likely that intent predicts onset (Sheppard, Hartwick, and Warshaw 1988). Research also indicates that prior smoking behavior is a strong predictor of future smoking among adolescents (Stacy, Bentler, and Flay 1994). Similarly, the advertising literature shows that prior product usage dominates the effects of advertising influences on intent and behavior (Vakratsas and Ambler 1999). Thus, we expect that prior trial behavior positively affects intent to smoke.

Prior research also shows a link between social influence and intent to smoke. For example, teens whose parents smoke are more likely to smoke because cigarettes are more readily available at home, and through the socialization process, teens model adult behavior (Smith and Stutts 1999). Studies also show pronounced linkages between smoking or intent to smoke and having friends or siblings who smoke (Kaufman et al. 2002; Romer and Jamieson 2001). As such, we expect that social influence positively affects intent to smoke.

$\mathrm{H}_{4}$ : Intent to smoke is positively affected by (a) trying cigarettes in the past (prior trial behavior) and (b) social influence (i.e., a sibling or friends who smoke, an adult smoker in the household).

Direct effects of ad campaign attitude on intent to smoke. In addition to the effects of prior trial behavior and social influence on intent to smoke, we anticipate that ad campaign attitude negatively affects intent to smoke. In the work of Armstrong and colleagues (1990), the perceived influence of cigarette advertisements outweighs parental, sibling, and peer smoking as a predictor of smoking behavior, and Smith and Stutts (1999) find that antismoking advertisements have a significant, negative effect on intent to smoke among adolescents. Such findings are consistent with the advertising literature that indicates that advertisements work on both cognitive and affective levels (Vakratsas and Ambler 1999) and that both cognitive (beliefs) and affective (attitude toward the ad) responses can have separate effects on intent (Burke and Edell 1989). Thus, if the antitobacco campaign is to be viewed as effective, ad campaign attitude should explain variance in intent to smoke in addition to that explained by prior trial behavior and social influence.

$\mathrm{H}_{5}$ : Favorable attitudes toward specific campaign advertisements (ad campaign attitude) negatively affect intent to smoke.

Interaction effects with ad campaign attitude. We predict that ad campaign attitude will interact with prior trial behavior and social influence to weaken their relationships with intent to smoke. We offer two reasons for this prediction. First, Vakratsas and Ambler (1999) stress that the interaction of affect and personal experience is needed to appreciate the processing and effectiveness of advertising fully. Smith and Swinyard (1982) also note that under normal ad-processing conditions, advertising may not result in higher levels of affective impact until a person considers his or her own trial and experience. In the context of smoking, passive learning of smoking imagery over time may reinforce perceptions of others' decision to smoke within peer groups or a person's own smoking trial behavior. As we previously indicated, Romer and Jamieson (2001, p. 132) predict that antitobacco advertising works by counteracting the diffusion of favorable images by disseminating either unfavorable images of smokers (or industry practices) or favorable images of nonsmokers.

Second, adolescents with prior usage of and exposure to social influence are likely to express greater intent to smoke. Intent for such adolescents also differs from that of adolescents who have antismoking beliefs and express little intent to smoke (Pechmann and Knight 2002). Affect (attitudes toward campaign advertisements) related to counteradvertising messages tends to cue and reinforce negative smoking perceptions among adolescents with prior smoking behavior or social influence. In turn, this should reduce the positive effects of the social and behavioral influences on intent to smoke. We expect relatively weaker effects of such ad-related outcomes for adolescents who have little direct exposure to smoking, a segment for which intent to smoke is already low and thus is more difficult to influence through antismoking campaigns (Pechmann et al. 2003). (In addition, it is likely that the campaign will reinforce nonsmoking adolescents' resolve not to smoke.) Overall, this rationale suggests that ad campaign attitude should attenuate the effects of prior trial behavior and social influence on intent. This suggests that the ad campaign attitude $\times$ prior trial behavior and ad campaign attitude $\times$ social influence interaction terms are negative and significant predictors of intent to smoke.

$\mathrm{H}_{6}$ : The positive effects of (a) prior trial behavior and (b) social influence on intent to smoke are attenuated by favorable attitudes toward campaign advertisements (ad campaign attitude).

Direct and mediating effects of beliefs. Empirical research indicates that beliefs about the consequences of a behavior are related to the intent to perform that behavior (Ajzen and Fishbein 1980) and that negative beliefs about the consequences of smoking are predictors of intent (Rind- 
fleisch and Crockett 1999). It has been shown that when intent is specific to a behavior in terms of target, action, context, and time, the ability of intent to predict behavior is enhanced (Ajzen and Fishbein 1980; Fishbein and Ajzen 1975). Thus, we predict that antismoking beliefs related to the campaign will negatively affect intent to smoke.

In Figure 1, antismoking beliefs (beliefs) also are positioned as a partial mediator of the effects that social influence, ad campaign attitude, and their relevant interactions have on intent to smoke. As we noted previously, adolescents are likely to have strongly held beliefs about smoking that serve as a primary predictor of intent (Slovic, Fischhoff, and Lichtenstein 1980). Thus, given this strong effect on intent to smoke, we expect that inclusion of antismoking beliefs in the model reduces the effects of social influence, ad campaign attitude, and the ad campaign attitude $\times$ prior trial behavior and ad campaign attitude $\times$ social influence interactions on intent to smoke. However, given the important role of affect in the evaluation of adolescents' smoking (Slovic 2001), the role of affect in judgment formation (Schwarz 1990), and the enduring impact of social influence on adolescents (John 1999), we do not expect that beliefs fully account for the effect of these independent variables on intent to smoke. Thus, our predictions for the direct and partial mediation effects of beliefs are as follows: 1

$\mathrm{H}_{7}$ : Antismoking beliefs (beliefs) (a) negatively affect intent to smoke and (b) partially mediate the effects of social influence, ad campaign attitude, and the ad campaign attitude $\times$ prior trial behavior and ad campaign attitude $\times$ social influence interactions on intent to smoke.

\section{Methodology}

\section{The Wisconsin Antitobacco Media Campaign}

As a result of the 1998 Master Settlement Agreement of the tobacco industry with the states, the Wisconsin Tobacco Control Board (WTCB; 2002) was created in 1999. An important objective of the board was to target antismoking programs and messages toward youths of middle and high school age. According to the CDC, $32.9 \%$ of high school students in Wisconsin were smokers, a rate higher than the national average (Campaign for Tobacco-Free Kids 2002). More than $\$ 6$ million (\$6.5 million total, or $\$ 1.21$ per capita) was allocated for the state's first major antitobacco advertising campaign (WTCB 2000). Because of the CDC's (1999) suggested minimum per capita allocations of $\$ 1.00$ and ideal per capita allocations of $\$ 3.00$ (Pechmann and Reibling 2000), the Wisconsin media campaign for 2001 provided an appropriate level of funding to help achieve exposure. A main objective of the youth campaign was to convey a message of industry deception and anti-imagery. This objective is consistent with recent successful programs

\footnotetext{
${ }^{1}$ Because prior behavior has been shown to be the strongest predictor of future smoking behavior (Stacy, Bentler, and Flay 1994), we do not hypothesize that the antismoking beliefs construct mediates the effect of prior behavior on intent to smoke.
}

that aimed to reduce and prevent adolescent smoking (cf. Bauer et al. 2000; Pechmann and Knight 2002; Perrachio and Luna 1998; Romer and Jamieson 2001) and with theory on attempts to persuade (Friestad and Wright 1994). Other important message themes focused on addiction and the harmful nature of secondhand smoke.

Four specific advertisements ("Janet," "Patrick," Mohammed," and "FACT") were placed in youth television and radio spots in seven major Wisconsin markets from July 2001 to December 2001. The advertisements had been successfully tested and run in other states (e.g., Massachusetts) and were recommended as part of CDC's best-practices list. "Janet" features a former cigarette model with a coarse voice talking about how she used to try to convince people to smoke and now tells people to stop smoking. "Patrick" shows a man talking about being part of a family of cigarette manufacturers and wanting people to know that they should not smoke. "Mohammed" is about a young African American man reading about ways the tobacco companies have tried to target kids to start smoking. Finally, in "FACT" (i.e., "Fighting Against Corporate Tobacco"), a cigarette company executive is dreaming about kids tracking him down and yelling at him about lies he has told about smoking. ${ }^{2}$

\section{Interviewing Procedure and Sample}

Telephone interviews were conducted with adolescents ranging in age from 12 to 18 years. The sample was based on a list purchased from a major list vendor, and telephone numbers of potential respondents were randomly selected from the list. Up to eight callbacks were made, for a response rate of $31 \%$ for adolescents who were known to be eligible for inclusion in the sample. The survey took between 10 and 15 minutes to complete. The introduction noted that the firm conducting the telephone interviews was doing "a survey of Wisconsin youth about their attitudes and opinions toward tobacco and other health issues." Parental permission to participate in the survey was obtained at the time of the interview for all respondents, and they were assured that their responses would remain confidential. The average age of respondents was 14.7 years, $97 \%$ were in grades 7 to $12,47 \%$ of the respondents were female, and $16 \%$ were African American. As such, the sample was quite similar to that of Wisconsin census figures. All data were collected in the latter portion of 2001, approximately six months after the antismoking campaign

2A media campaign aimed at young adults directly focused on the following message themes: (1) secondhand smoke kills and (2) nicotine is addictive and tobacco is deadly. These messages served as additional objectives for adolescents; there were spillover effects of the young adult campaign for the adolescents. Given the results of the confirmatory factor analyses we describe subsequently, we decided that one beliefs construct related to the three message themes was relevant and appropriate for tests of hypotheses. Because we assessed hypotheses using a field study, we acknowledge that the industry deception, addiction, and secondhand smoke beliefs may be potentially influenced by other sources of information at the time of the campaign. 
first began airing. Across all analyses, the sample sizes used ranged from $n=924$ to $n=943$.

\section{Measures}

Measures were drawn from previous state surveys, including the University of Massachusetts Tobacco Study Youth Instrument, Florida's Anti-Tobacco Media Evaluation Survey, the California Adult Tobacco Survey, and the CDC's Youth Tobacco Survey and Youth Risk Behavior Survey. All measures and procedures were pretested with 75 respondents before the survey was conducted.

Independent and control variables. We assessed prior trial behavior by asking respondents whether they had ever tried smoking cigarettes, even one or two puffs (no $=0$, yes $=1$ ). Three items measured social influence. The first item asked respondents whether they had a sibling who smoked (no $=0$, yes $=1)$, the second asked whether there was an adult smoker in the household (no $=0$, yes $=1)$, and the third asked whether they had any friends (among their four closest friends) who smoked (no $=0$, yes $=1)$. We summed the scores of these three items (sibling, adult smoker, and friends) to form one overall social influence composite that ranged from 0 to 3 , such that a higher score suggested a stronger influence to smoke. Respondents were screened such that they had to recall at least one campaign advertisement to ensure a basis for a campaign attitude. For advertisements recalled, respondents rated their attitude toward the specific advertisements by indicating how much they liked each campaign advertisement on a ten-point scale ( $0=$ "did not like the ad at all," $10=$ "liked it very much"). We summed these ratings and averaged them to form the ad campaign attitude measure. We also included measures of age, gender $(0=$ female, $1=$ male), and race (African American $=0$, Caucasian $=1$ ) as control variables in all analyses.

Dependent variables. We measured both dependent variables in the model with multiple items. Antismoking beliefs related to the campaign pertained to three message themes: (1) deceptiveness of the tobacco companies in their marketing practices, (2) the harmfulness of secondhand smoke, and (3) the addictiveness of smoking cigarettes. Within each of these themes, we summed the scores on four items rated on four-point "strongly disagree/agree" scales and then averaged them to form an overall theme composite. We summed and averaged the three composite scores to form indicators for one overall antismoking beliefs construct (beliefs). We measured intent to smoke with three items on four-point "definitely no/definitely yes" scales. For the three indicators of the beliefs construct and the three items of the intent construct, standardized loadings from confirmatory factor models ranged from .65 to .95 , and average variance extracted estimates for each of these multi-indicator/item measures exceeded .50 (Fornell and Larcker 1981). The Appendix shows all measures, and Table 1 reports all correlations and reliability estimates.

Measurement checks. We conducted analyses to determine whether antismoking beliefs should be represented as indicators of one overall construct. First, in a confirmatory factor analysis, we specified the beliefs construct as a higher-order factor with the three themes (i.e., deceptiveness of the tobacco companies in their marketing practices, harmfulness of secondhand smoke, and addictiveness of smoking cigarettes) as first-order factors. We then specified the individual items used to assess each theme as manifest indicators of their respective first-order factors. We used three indexes to examine the fit of this model: (1) the comparative fit index (CFI), (2) the nonnormed fit index (NNFI), and (3) the root mean square error of approximation (RMSEA). Values in the mid- to high- 90 range indicate good fit for the CFI and NNFI, and values of .08 and less indicate good fit for the RMSEA ( $\mathrm{Hu}$ and Bentler 1999). The higher-order model fit the data well $\left(\chi^{2}=73.97\right.$, degrees of freedom [d.f.] $=51 ; \mathrm{CFI}=.99 ; \mathrm{NNFI}=.98$; RMSEA = .02) $(\mathrm{Hu}$ and Bentler 1999), and the standardized loadings of the first-order factors to the higher-order factor ranged from .74 to $.95(p<.01)$, indicating a high degree of convergence among the first-order factors (Bagozzi and Heatherton 1994). Furthermore, the composite reliability estimates (estimates analogous to coefficient alpha) for the manifest indicators to their first-order factors were .78 for the deceptiveness of the tobacco companies in their marketing practices, .72 for the harmfulness of secondhand smoke, and .80 for the addictiveness of smoking cigarettes.

Second, we conducted a series of t-tests between dependent correlations to determine whether the three beliefs

TABLE 1

Means, Standard Deviations, and Correlations Among Constructs

\begin{tabular}{|c|c|c|c|c|c|c|c|c|c|}
\hline & Mean & $\begin{array}{l}\text { Standard } \\
\text { Deviation }\end{array}$ & 1 & 2 & 3 & 4 & 5 & 6 & 7 \\
\hline 1. Prior trial behavior & .27 & .44 & - & & & & & & \\
\hline 2. Social influence & .72 & .86 & .48 & - & & & & & \\
\hline 3. Ad campaign attitude & 7.31 & 2.11 & -.19 & -.20 & .76 & & & & \\
\hline 4. Ad campaign attitude $\times$ prior trial behavior & - & - & -.23 & -.22 & .60 & - & & & \\
\hline 5. Ad campaign attitude $\times$ social influence & - & - & -.14 & -.20 & .27 & .56 & - & & \\
\hline 6. Beliefs & 3.29 & .38 & -.16 & -.16 & .30 & .29 & .12 & .79 & \\
\hline 7. Intent & 1.34 & .62 & .54 & .44 & -.29 & -.40 & -.30 & -.30 & .85 \\
\hline
\end{tabular}

Notes: Italicized entries on the diagonal for Variables 3, 6, and 7 are coefficient alpha estimates of internal consistency. All correlations are statistically significant $(p<.01)$. 
individually had different correlations with ad campaign attitude (an antecedent of beliefs) and intent to smoke (a consequence of beliefs). For example, to test whether the correlation between the belief of addictiveness of smoking cigarettes and intent to smoke differed from the correlation between the belief of harmfulness of secondhand smoke and intent to smoke, we used the procedure that Cohen and Cohen (1983, pp. 56-57) recommend. Across all correlational comparisons ( $\mathrm{six}$ in total), we found no significant differences ( $\mathrm{t}$-values ranged from .92 to $1.23, p>.10$ ). Thus, the relationships between the beliefs about the deceptiveness of the tobacco companies, the harmfulness of secondhand smoke, and the addictiveness of smoking cigarettes and ad campaign attitude and intent to smoke did not differ. In summary, we found evidence for a single antismoking beliefs construct.

\section{Analysis and Results}

Consistent with the procedures of Holmbeck (1997), we used structural equation modeling (SEM) as our analytical approach. This approach allows for an assessment of the incremental effects of the campaign-related constructs and their interactions after the effects of prior trial behavior and social influence have been taken into account. This approach also incorporates the potentially biasing impact of measurement error on path estimates. For beliefs and intent to smoke, we accounted for error in measurement by allowing the SEM package (LISREL 8) to estimate item/indicator loadings and measurement error terms freely. For ad campaign attitude, we used its summed item score and set its measurement loading to the square root of its internal consistency estimate and its error term to 1 - coefficient alpha $\times$ construct variance to account for measurement error (Jöreskog and Sörbom 1982). For all other single indicator constructs (i.e., prior trial behavior, social influence, and the interaction terms), we set item loadings to 1 and error terms to 0 . Consistent with prior smoking research, we accounted for any demographic effects by entering age, gender, and race as control variables for all models estimated.

\section{Effects on Antismoking Beliefs}

$H_{1}-H_{2}$ : Direct effects. Panel A of Table 2 presents the results that pertain to beliefs. $\mathrm{H}_{1}$ predicts that prior trial behavior $\left(\mathrm{H}_{1 \mathrm{a}}\right)$ and social influence $\left(\mathrm{H}_{1 \mathrm{~b}}\right)$ negatively affect antismoking beliefs related to the campaign (beliefs). Model 1 examines the two direct effect predictions, and the evidence shows that $\mathrm{H}_{1 \mathrm{a}}$ and $\mathrm{H}_{1 \mathrm{~b}}$ are supported. Across fit indexes (CFI, NNFI, and RMSEA), the model fits the data well, and both prior trial behavior and social influence negatively affect antismoking beliefs. $\mathrm{H}_{2}$ predicts that ad campaign attitude positively affects beliefs, and Model 2 tests this prediction by adding ad campaign attitude to the model. Model 2, which includes the direct effects of all three predictors, also fits the data well, and the difference in fit between Model 1 and Model 2 is significant $\left(\chi^{2}\right.$ diff $=64.21$, d.f. diff $=1, p<.01)$. This difference between the models indicates that the inclusion of ad campaign attitude explains an additional $8 \%$ of the variance in beliefs that was not previously explained by prior trial behavior and social influ- ence. In total, prior trial behavior, social influence, and ad campaign attitude account for $13 \%$ of the variance in beliefs.

$\mathrm{H}_{3}$ : Interaction effects of ad campaign attitude on beliefs. We predict that ad campaign attitude attenuates the negative effects of prior trial behavior $\left(\mathrm{H}_{3 \mathrm{a}}\right)$ and social influence $\left(\mathrm{H}_{3 b}\right)$ on antismoking beliefs. Thus, we expect that the interactions of prior trial behavior and social influence with ad campaign attitude are positive and significant predictors of beliefs. We mean-centered ad campaign attitude and social influence before creating the interaction terms (Aiken and West 1991), and then we added the interaction terms hierarchically to the predictors already in Model 2 to form Model 3. As is shown in Panel A of Table 2 , Model 3 fits the data well and is significantly better fitted than Model $2\left(\chi^{2}\right.$ diff $=10.74$, d.f. diff $\left.=2, p<.01\right)$. This significant difference between models indicates that the predicted interactions explain additional variance in beliefs. Thus, $\mathrm{H}_{3 \mathrm{a}}$ is supported; the ad campaign attitude $\times$ prior trial behavior interaction term positively affects and incrementally explains $2 \%$ of the variance in beliefs. However, the coefficient for the interaction of social influence and ad campaign attitude is not significant and thus does not support $\mathrm{H}_{3 b}$.

\section{Effects on Intent to Smoke}

$H_{4}-H_{5}$ : Direct effects. We predict that prior trial behavior $\left(\mathrm{H}_{4 \mathrm{a}}\right)$ and social influence $\left(\mathrm{H}_{4 \mathrm{~b}}\right)$ have positive effects on intent to smoke, and tests of the predictions are presented in Model 1, Panel B, in Table 2. Model 1 fits the data well and supports these predictions, as both prior trial behavior and social influence are significant predictors and explain $41 \%$ of the variance in intent to smoke. We also predict that ad campaign attitude $\left(\mathrm{H}_{5}\right)$ negatively affects intent and explains variance in addition to the effects of prior trial behavior and social influence. Model 2 in Panel B of Table 2 supports this hypothesis. Model 2 has a better fit than Model $1\left(\chi_{\text {diff }}^{2}=39.12\right.$, d.f. diff $\left.=1, p<.01\right)$, and all three constructs (prior trial behavior, social influence, and ad campaign attitude) affect intent in the predicted direction. The addition of ad campaign attitude has a negative effect on intent and explains an additional $3 \%$ of the variance in this construct.

$H_{6}$ : Interaction effects of ad campaign attitude on intent. $\mathrm{H}_{6}$ predicts that ad campaign attitude interacts with prior trial behavior and social influence such that ad campaign attitude has a stronger (and more negative) influence on intent to smoke for adolescents with prior trial behavior $\left(\mathrm{H}_{6 \mathrm{a}}\right)$ and with social influence $\left(\mathrm{H}_{6 \mathrm{~b}}\right)$. Thus, we anticipate that the interaction terms ad campaign attitude $\times$ prior trial behavior and ad campaign attitude $\times$ social influence are negative and significant predictors of intent to smoke. We added the mean-centered interaction terms hierarchically to the predictors already in Model 2 to create Model 3. Model 3 fit better than Model $2\left(\chi_{\text {diff }}^{2}=71.80\right.$, d.f. diff $\left.=2, p<.01\right)$, which suggests that the addition of the interaction terms explains incremental variance in intent. Both the ad campaign attitude $\times$ prior trial behavior and the ad campaign attitude $\times$ social influence interaction terms are significant 
TABLE 2

Hierarchical SEM Results for Antismoking Beliefs and Intent to Smoke

A. Results with Antismoking Beliefs as Dependent Variable $(n=943)$

Fit Estimates

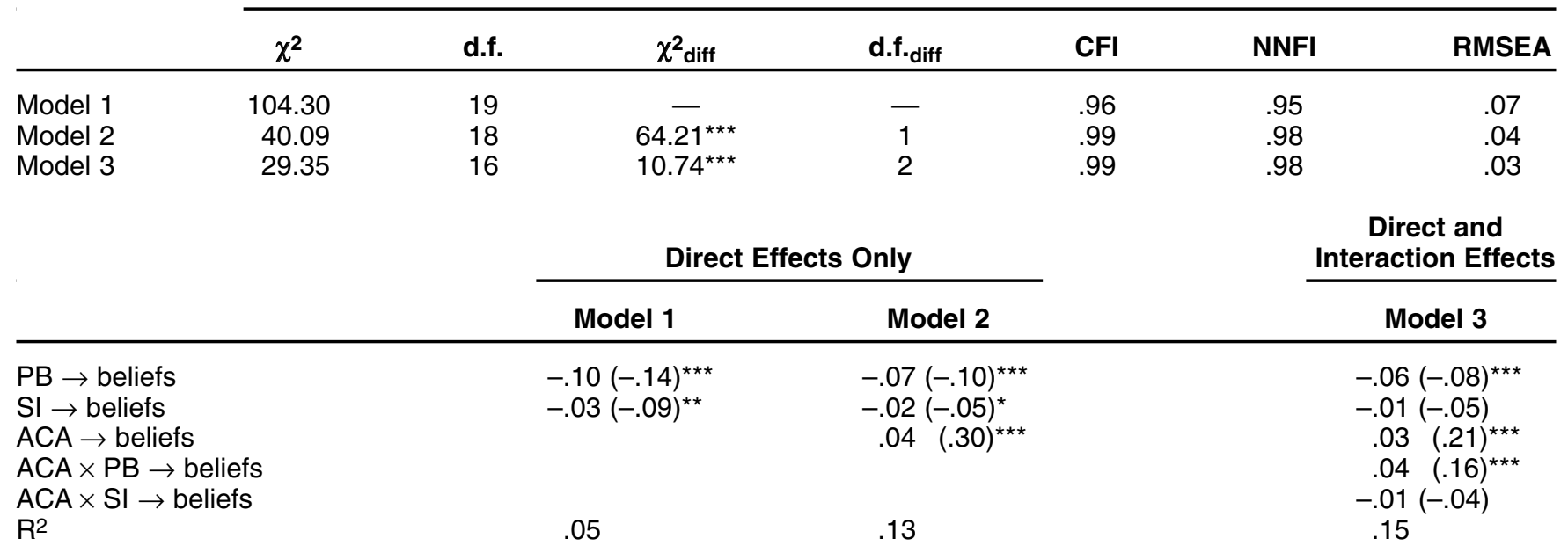

B. Results with Intent to Smoke as Dependent Variable $(n=924)$

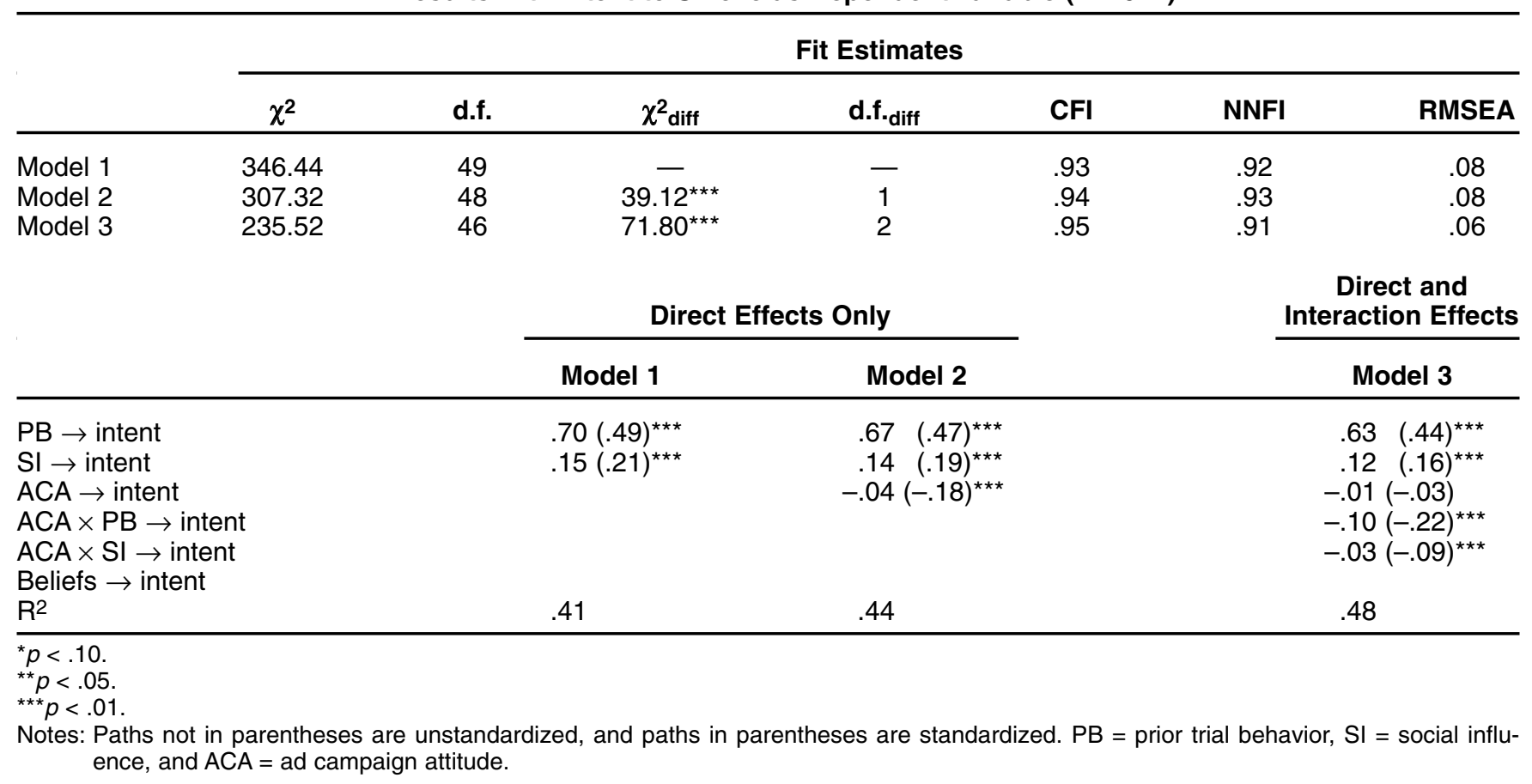

$(p<.01)$ and negative, as we predicted, in support of $\mathrm{H}_{6}$. The interaction terms explain an additional $4 \%$ of the variance in intent to smoke. ${ }^{3}$

${ }^{3}$ Given the four advertisement themes, three belief themes, and three types of social influence (friends, siblings, or adults in the home), we conducted several analyses that disaggregated the ad campaign attitude, beliefs, and social influence measures. First, in general, attitudes toward each of the four campaign advertisements were consistent and favorable; mean scores on a zero-to-ten scale ranging from 7.04 to 7.78. Correlations of the attitude measure for each of the four specific advertisements with the beliefs measure ranged from .20 to $.29(p<.01)$ and from -.23 to $-.27(p<.01)$ for the intent measure.

Second, because specific advertisements of the campaigns were more closely related to tobacco company deceptive practices, we also estimated all models shown in Tables 2 and 3 with only deceptiveness of the tobacco companies as the beliefs measure. In terms of statistical significance and coefficient magnitude, all independent variables that predicted beliefs (using only the deceptiveness measure) were similar to the ones in Tables 2 and 3. Use of the deceptiveness measure as a predictor of smoking intent also yielded similar results to the ones in Tables 2 and 3. Third, we analyzed each social influence separately. The results are similar to the ones in Table 2 for beliefs and intent, with the exception that the ad campaign attitude $\times$ friends interaction term affected 
To explore the specific nature and implications of these interactions further, we examined correlational results for (1) adolescents with and without prior smoking trial behavior and (2) adolescents with and without social influence. For adolescents with prior trial behavior, the correlation of ad campaign attitude with intent to smoke is $-.38(p<.01)$, and for adolescents without prior trial behavior, the correlation is -.07 ( $p<.05$, one-tailed test). The difference in the correlations between ad campaign attitude and intent for adolescents with and without prior trial behavior is statistically significant $(\mathrm{t}=4.52, p<.01)$. For adolescents with social influence, the correlation of ad campaign attitude with intent is -.35 , and for adolescents without social influence, the correlation is $-.06(\mathrm{t}=4.63, p<.01)$. These correlational differences are consistent with the significant interaction terms between prior trial behavior and ad campaign attitude and between social influence and ad campaign attitude, shown in Panel B of Table 2. As we hypothesized, they suggest that a favorable campaign attitude has a stronger (and more negative) impact on intent to smoke for adolescents with prior trial behavior and for adolescents exposed to social influence. ${ }^{4}$

$H_{7}$ : Effects of beliefs on intent and mediation analyses. To determine whether the beliefs construct mediates the effects of prior trial behavior, social influence, ad campaign attitude, ad campaign attitude $\times$ prior trial behavior, and ad campaign attitude $\times$ social influence on intent, four conditions must hold: (1) The predictor variables (prior trial behavior, social influence, ad campaign attitude, ad campaign attitude $\times$ prior trial behavior, and ad campaign attitude $\times$ social influence) must affect the mediator (beliefs) in the predicted direction, (2) the mediator (beliefs) must affect the dependent variable (intent to smoke) in the predicted direction, (3) the predictor variables must affect the dependent variable (intent to smoke) in the predicted direc-

beliefs, and the ad campaign attitude $\times$ sibling and the ad campaign attitude $\times$ adult interaction terms did not. The ad campaign attitude $\times$ prior trial behavior term remained significant for intent across all disaggregated social influence models.

Finally, it is important to know whether there are any differences in the relative abilities of the four advertisement themes to predict smoking intent for adolescents who had and had not tried smoking in the past. For adolescents who had not tried smoking, the correlations of each advertisement with intent ranged from -.03 ("Mohammed") to -.08 ("Janet"), without any significant differences across the correlations (Cohen and Cohen 1983). For adolescents who had tried smoking, the correlations of each advertisement with intent ranged from -.24 ("FACT") to -.46 ("Mohammed"), again without any significant differences across the correlations.

${ }^{4} \mathrm{We}$ also performed similar tests for the beliefs measure. For adolescents with prior trial behavior, the correlation of ad campaign attitude with beliefs is .47 ; for adolescents without prior trial behavior the correlation is $.20(\mathrm{t}=4.05, p<.01)$. For adolescents with social influence, the correlation of ad campaign attitudes with beliefs is .34; for adolescents without social influence the correlation is $.24(\mathrm{t}=1.67, p<.05$, one-tailed test). As with intent, the results suggest that a favorable ad campaign attitude has a greater positive impact on antismoking beliefs for adolescents with prior trial behavior and social influence. tion, and (4) the impact of the predictors on the dependent variable (intent to smoke) must be not significant (full mediation) or reduced (partial mediation) after controlling for the mediator (beliefs) (Baron and Kenny 1986; Holmbeck 1997).

The first two conditions are largely satisfied by Model 1 (the fully mediated model) in Table 3. Consistent with the previous analyses, all predictor variables (with the exception of ad campaign attitude $\times$ social influence) affect beliefs, and beliefs affect intent. The effect of beliefs on intent supports $\mathrm{H}_{7 \mathrm{a}}$, and this model also shows adequate fit indexes. The third condition is satisfied by Model 2, in which the predictor variables affect the dependent variable. As is shown in Table 3, this "predictor variable affects dependent variable" model estimates only the effects of the predictor variables on the dependent variable of intent. This model fits well, and with the exception of the ad campaign attitude $\rightarrow$ intent path, all predictor variables affect intent. The fourth condition is satisfied if the effects of the predictor variables (prior trial behavior, social influence, ad campaign attitude, ad campaign attitude $\times$ prior trial behavior, and ad campaign attitude $\times$ social influence) on the dependent variable (intent) become nonsignificant when controlling for the effects of the mediator. Model 3 (no-mediation model) in Table 3 accounts for the effects of the predictor variables on the proposed mediator (beliefs) and for the effect of the mediator on the dependent variable. If full mediation exists, the fit of Model 3 (no mediation) should not be significantly better than the fit of Model 1 (fully mediated), and the path estimates of Model 3 for the predictor variables to the dependent variable should not be significant. As is shown in Table 3, this is not the case. The fit of Model 3 is significantly better than the fit of Model 1 $\left(\chi_{\text {diff }}=363.29\right.$, d.f. diff $\left.=5, p<.01\right)$, and four of the five Model 3 paths from the predictor variables to the dependent variable are significant. Furthermore, the paths are virtually identical in magnitude to the paths of Model 2 (in which the mediator is not included), which suggests that the paths also are not partially mediated. In summary, the effects of prior trial behavior, social influence, ad campaign attitude, ad campaign attitude $\times$ prior trial behavior, and ad campaign attitude $\times$ social influence on intent are not mediated by beliefs, and $\mathrm{H}_{7 \mathrm{~b}}$ is not supported. Therefore, the moderating effects of ad campaign attitude on prior trial behavior and social influence on intent remain after we introduced beliefs as a mediator in the model. 5

5Partial mediation is supported if the effects of the predictors on the dependent variable are significantly diminished after accounting for the mediator. Thus, we tested whether the regression coefficients for social influence, ad campaign attitude, ad campaign attitude $\times$ prior trial behavior, and the ad campaign attitude $\times$ social influence were lower when we controlled for the effect of beliefs. Using linear regression and equations suggested by Kenny, Kashay, and Bolger (1998), we found that partial mediation was not statistically supported for any predictor variable. That is, there were no significant differences between the predictor variable coefficients with or without the effects of beliefs being controlled.

We attempted to test the extent to which common methods variance affected our results using Netemeyer and colleagues' (1997) 
Table 3

Results of Mediation Analysis

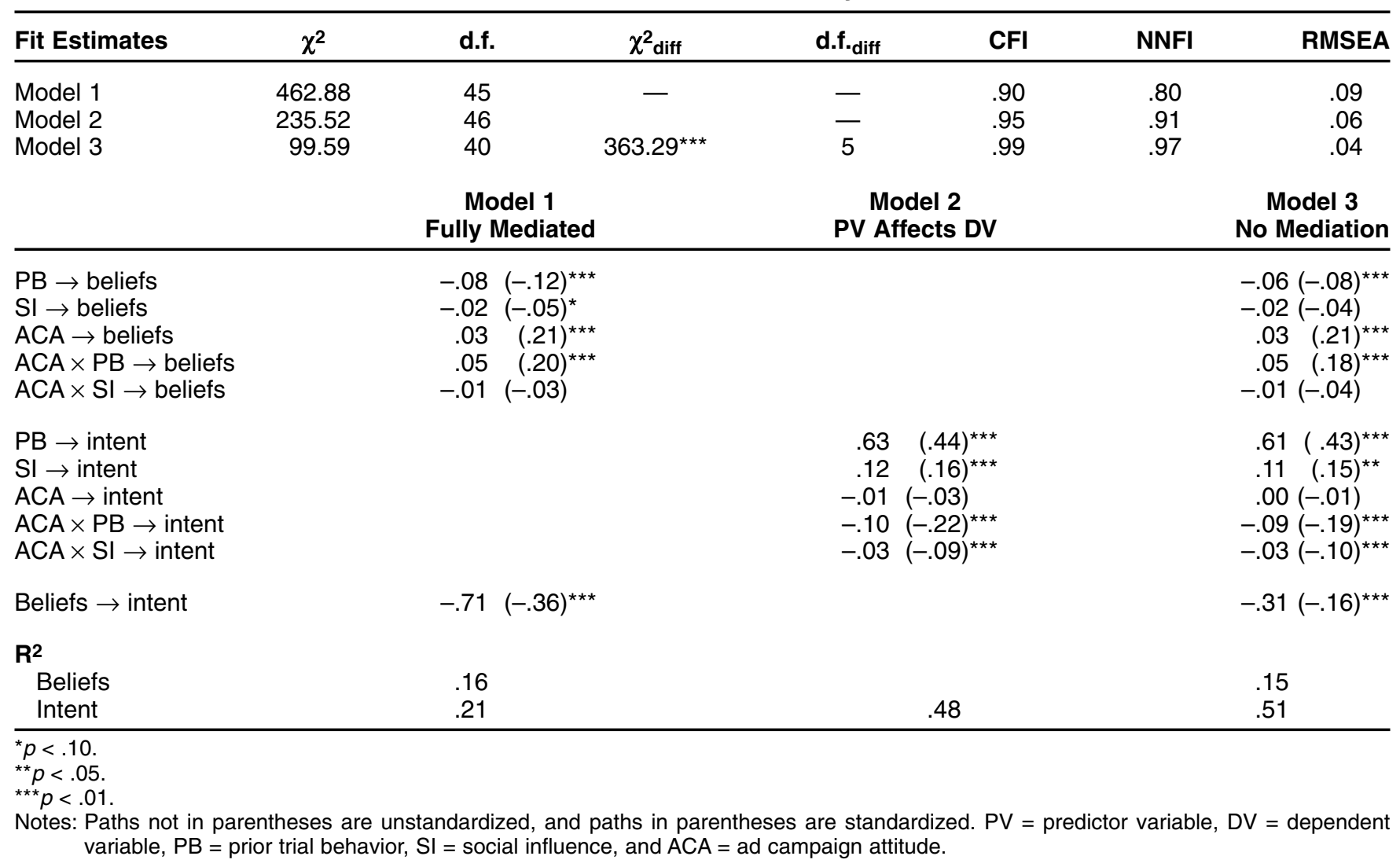

\section{Discussion and Implications}

Given estimates that 6.4 million of today's adolescents are likely to die prematurely because of their decision to smoke cigarettes, and given the continuing promotional activities of tobacco companies (CDC 2002), furthering the understanding of the effectiveness of countermarketing campaigns in reinforcing antismoking beliefs and in reducing adolescent smoking intent is important. Our research used a field study for a $\$ 6.5$ million antismoking campaign to address two primary questions: (1) Do counteradvertising campaign attitudes directly affect antismoking beliefs and intent in a manner similar to that of conventional advertisements? and (2) Can ad campaign attitudes have a stronger effect on beliefs and intent for adolescents with prior smoking trial behavior and for adolescents exposed to social

procedures. Tests for common method effects using SEM required direct (linear) effects and multiple-item measures for the constructs. Given these requirements, we estimated the potential biasing impact of common methods for the beliefs $\rightarrow$ intent path. With this test, we found no evidence that common methods variance attenuated the beliefs $\rightarrow$ intent path.

We also conducted analyses to assess the effects of some key variables that we did not include in our model estimation (e.g., price of cigarettes, parental vigilance, academic performance, parents' education level). Our analyses revealed that the omitted variables were not likely to account for the effects we report in our model estimation. The analyses are also available on request. influence (i.e., friends or siblings who smoke or an adult smoker in the home)? Our results suggest that the answer to both questions is yes, because ad campaign attitudes, prior trial behavior, and social influence all directly affected antismoking beliefs and intent to smoke. Furthermore, ad campaign attitude interacted with prior trial behavior to strengthen antismoking beliefs; in turn, ad campaign attitude also interacted with social influence and prior trial behavior to attenuate adolescent intent to smoke. On the basis of our results confirming eight of ten hypotheses, we found considerable support for the proposed relationships. We discuss implications of these results next.

\section{Implications for Counteradvertising Programs and Public Policy}

Direct and indirect effects. Our study offers implications for advertisers, social marketers, the public health community, and public policy officials on the use of counteradvertising to affect message-related beliefs and intent. These implications stem from the direct, indirect, interaction, and mediating effects that we found in the study. Given the direct and strong effect of prior smoking trial behavior on intent, our study suggests that similar antismoking campaigns can be used to help reduce continued smoking experimentation by adolescents. Creative ways of reducing continued trial may affect intent for adolescents both directly and indirectly through the networks of friends who smoke. For example, although many antismoking cam- 
paigns have focused primarily on cognitive-based reasons not to smoke, recent results suggest that affective approaches may be beneficial in counteracting favorable images for peers evoked in cigarette advertising (Pechmann et al. 2003; Perrachio and Luna 1998). Such an approach was used in our campaign and is consistent with work on understanding persuasion influence (Friestad and Wright 1994). We also found that adolescents' antismoking beliefs can be directly influenced by attitudes toward campaign advertisements. The incremental variance in beliefs explained by this campaign-related affective construct $(8 \%)$ again demonstrates that well-designed antismoking campaigns can affect adolescents' smoking-related beliefs (Siegel and Biener 2000).

Interaction effects. Our study extends findings from other field studies by examining how ad campaign attitude interacts with prior trial behavior and social influence. Our results show that ad campaign attitude attenuates the influence of prior trial behavior on antismoking beliefs and intent to smoke. There also is partial support for the interaction effect of the ad campaign attitude construct for social influence in the case of intent, but not for antismoking beliefs; only the ad campaign attitude $\times$ friends interaction term had a significant and positive effect on antismoking beliefs. However, this latter finding indicates that counteradvertising campaigns, such as the one used in the present study, can be successful in lessening the influence of smoking peers on adolescent smoking beliefs held. The ad campaign attitude $\times$ friends interaction also helps extend prior research on the direct impact of antismoking advertisements on both adolescent health-risk beliefs (Pechmann et al. 2003) and adolescent antismoking beliefs (Pechmann and Knight 2002). However, overall (i.e., across all social influence types), it should be noted that the strength of ad campaign attitude is similar in our study for adolescents with and without social influence.

For smoking intent, results from Table 2 suggest that a favorable ad campaign attitude operates primarily through a negative impact on smoking intent for adolescents with prior smoking experience and for adolescents with social influence. Because these at-risk segments have developed a stronger intent to smoke, a greater opportunity exists to reduce smoking intent through antismoking ad campaigns, such as the one used in the present study. In total, our results show that the interaction effects with antismoking campaign attitude explained an additional $4 \%$ of the variance in intent to smoke.

Our interaction results are also consistent with recent experimental work by Pechmann and colleagues (2003, p. 9), who use advertisements with social disapproval messages. Their results suggest that special strategies and executions may be needed for adolescents who are susceptible to becoming smokers on a more permanent basis or who consider themselves invulnerable to long-term risks. In our case, we found success for executions that stressed industry deception and harmful effects through the use of advertising spokespeople. In general, we view our results that favorable campaign attitudes have stronger negative effects on smoking intent for segments with prior experience and close exposure to smokers as supportive for the potential of positive outcomes for carefully designed countermarketing campaigns. However, such positive outcomes have not always been found (cf. Romer and Jamieson 2001), and the direct measurement of important influencing factors, such as prior smoking trial behavior and social influence, should be considered so that the potential effectiveness of campaign efforts is not diluted.

Mediation effects. We also hypothesized that antismoking beliefs would partially mediate the effects of social influence, ad campaign attitude, and the interactions of campaign attitude with prior trial behavior and social influence on intent. Although the results show that beliefs failed to mediate the ad campaign attitude and interaction effects even partially, they suggest a potentially important implication. That is, ad campaign affect can have a significant and negative impact on personal smoking intent that is not accounted for by antismoking beliefs, especially for adolescents who could benefit most from the campaign (i.e., ones with prior smoking trial or exposed to social influence). The effect of the ad campaign attitude interactions coupled with the significant, direct (but not mediating) effect of beliefs on intent also suggests that the affective and cognitive aspects related to a countermarketing campaign can operate independently of each other in terms of their effects on consequences (Schwarz 1990). Moreover, our results are consistent with prior adolescent smoking research that demonstrates the importance of affective reactions in the evaluation of smoking and antismoking stimuli (cf. Pechmann and Knight 2002; Romer and Jamieson 2001).

\section{Contributions to Marketing Knowledge}

It has been proposed that affective responses to advertising can interact with product usage experience, and the relative influence of each is dependent on the product category and other contextual factors (Vakratsas and Ambler 1999, p. 36). Consistent with this view, our direct effects show that for a highly visible, mature product category such as cigarettes, prior behavior and social influence strongly influence intent. However, our results also indicate that cognitive ad campaign outcomes (e.g., antismoking beliefs related to the campaign) can have direct effects on intent to smoke, whereas affective ad campaign outcomes (e.g., ad campaign attitude) can have important interaction effects on intent to smoke. Such separate processing routes are consistent with tenets of the elaboration likelihood model, which shows that one's elaboration on affect can be as persuasive at times as that of cognitive beliefs (Petty and Cacioppo 1986, pp. 213 14). Thus, although a counteradvertising campaign attempts to convince target consumers not to engage in a particular behavior, the results support the hypothesized interactions between affective campaign responses and both prior trial behavior and social influence effects. As such, our study extends prior research on advertising effects (Vakratsas and Ambler 1999) to (1) a counteradvertising campaign and (2) prior trial behavior and social influences that encourage intent. In addition, an examination of our model of counteradvertising, prior trial behavior, and social influence indicates that it is capable of accounting for a substantial portion (i.e., 48\%) of variance in smoking intent. 


\section{Further Research}

As reviewed by Pechmann (1997, p. 198), a variety of approaches have been used to study the effects of antismoking ad campaigns, and now include cross-sectional (Romer and Jamieson 2001) and longitudinal (Popham et al. 1994) field studies, controlled lab experiments (Pechmann and Knight 2002; Pechmann et al. 2003), and qualitative research (Peracchio and Luna 1998). In our study, we used cross-sectional field data for a six-month counteradvertising campaign. Although our results are encouraging, the crosssectional design prohibits us from drawing causal inferences. Longer-running field studies with longitudinal data that use the same set of respondents are desirable and could provide insight into long-term cessation rates and overall levels of smoking among adolescents (Schar and Gutierrez 2001). (For example, the CDC [1999] recommends media campaigns of several years to achieve behavioral outcomes for actual smoking rates.) Other field studies could have respondents keep ad diaries, or "metered" exposure data could be obtained for some time period, and effects on subsequent cessation and initiation rates could be assessed. In addition, in the case of actual antismoking field campaigns, researchers (with input from state tobacco control boards) must weigh the appropriate mix of counteradvertising campaign messages with other beneficial programs (e.g., school-based programs, community outreach efforts) to determine the most efficient use of the funds available for adolescent smoking prevention and cessation. Experimental research, varying exposure levels over different time frames and regions, may also provide insight into the relationships tested in this study by measuring attitudes and intent across groups with and without prior behavior. In general, research has shown that negative information has stronger effects than positive information because it may be viewed as more diagnostic in decision making (Kahneman and Tversky 1979). Experiments designed to address the impact of antismoking information presented in the context of protobacco company promotions across adolescents with and without prior trial behavior and social influence would be of interest (cf. Pechmann and Ratneshwar 1994).

Other research might consider variables not measured in our study. For example, increases in price are believed to reduce adolescent intent and behavior with respect to smoking (Chaloupka et al. 2002). Thus, the strength of a pricing effect relative to long-term advertising effects and the ability of marketing-mix variables to complement one another would be of interest. On a broader level, the marketing and public health literature on how outcomes of countermarketing media campaigns may moderate the positive effects of prior experience and social and family influences on intent and long-term behavior is in need of greater study. Comprehensive prevention programs (including countermarketing campaigns) might examine other factors such as school misbehavior and academic failure (Bryant et al. 2002), positive parental involvement (Simons-Morton 2002), and related problem behaviors in an effort to help reduce adolescent smoking intent and use. In addition, further research might address similar direct, interacting, and mediating effects for other adolescent countermarketing campaigns that involve drug and alcohol consumption (Block et al.
2002; Rose, Bearden, and Manning 1996). Finally, our study findings point to the importance of accounting for key underlying characteristics of the target population in the assessment of countermarketing campaigns. Studies that examine general adolescent populations while ignoring the measurement of important factors such as prior trial behavior and social influence may mask significant effects of the campaign. In summary, we encourage the consideration of these issues to help improve the understanding of the problem consumption behaviors of adolescents while enhancing future consumer and societal welfare.

\section{Appendix Measurement Items}

\section{Social Influence}

Do you have any brothers or sisters who currently smoke cigarettes? (Sibling)

Is there an adult in your household who is a regular smoker? (Adult smoker)

How many of your four closest friends smoke cigarettes? (Friends)

\section{Prior Trial Behavior}

Have you ever tried cigarette smoking, even one or two puffs?

\section{Ad Campaign Attitude}

For each of the four specific advertisements in the campaign, respondents were asked, "How much did you like the advertisement?"

\section{Antismoking Beliefs}

\section{Tobacco Company Deception Beliefs}

Tobacco companies specifically try to get young people to start smoking.

Tobacco companies fool young people into believing smoking is okay.

Tobacco companies encourage people to start smoking.

Tobacco companies use deceptive practices to get people hooked on smoking.

\section{Secondhand Smoke Beliefs}

Breathing smoke from someone else's cigarette is harmful.

Secondhand smoke is dangerous to nonsmokers.

Secondhand smoke is not as dangerous as people make it out to be. (Reverse coded)

Secondhand smoke kills people.

Smoking Addictiveness Beliefs

Smoking is addictive.

Nicotine is physically addictive.

Tobacco is a deadly product in any form.

Tobacco is a dangerous product.

\section{Intent to Smoke}

If one of your best friends offered you a cigarette, would you smoke it?

Do you think you will smoke a cigarette at anytime during the next year?

Do you think you will be smoking cigarettes five years from now? 


\section{REFERENCES}

Aiken, Leona S. and Stephen G. West (1991), Multiple Regression: Testing and Interpreting Interactions. Newbury Park, CA: Sage Publications.

Ajzen, Icek and Martin Fishbein (1980), Understanding Attitudes and Predicting Social Behavior. Englewood Cliffs, NJ: Prentice Hall.

Aloise-Young, Patricia A., John W. Graham, and William B. Hansen (1994), "Peer Influence on Smoking Initiation During Early Adolescence: A Comparison of Group Members and Group Outsiders," Journal of Applied Psychology, 79 (2), 281-87.

Armstrong, B.K., N.H. de Klerk, R.E. Shean, D.A. Dunn, and P.J. Dolin (1990), "Influence of Education and Advertising on the Uptake of Smoking by Children," Medical Journal of Australia, 152 (3), 117-24.

Bagozzi, Richard P. and Todd F. Heatherton (1994), "A General Approach to Representing Multifaceted Personality Constructs: Application to State Self-Esteem," Structural Equation Modeling, 1 (1), 35-67.

Baron, Reuben M. and David A. Kenny (1986), "The ModeratorMediator Variable Distinction in Social Psychological Research: Conceptual, Strategic, and Statistical Considerations," Journal of Personality and Social Psychology, 51 (6), 1173-82.

Barton, John, Laurie Chassin, Clark C. Presson, and Steven J. Sherman (1982), "Social Image Factors as Motivators of Smoking Initiation in Early and Middle Adolescence," Child Development, 53 (6), 1499-1511.

Bauer, Ursula E., Tammie M. Johnson, Richard S. Hopkins, and Robert G. Brooks (2000), "Changes in Youth Cigarette Use and Intentions Following Implementation of a Tobacco Control Program: Findings from the Florida Youth Tobacco Survey, 1998-2000," Journal of the American Medical Association, 284 (6), 723-28.

Bem, D.J. (1967), "Self-Perception: An Alternative Interpretation of Cognitive Dissonance Phenomena," Psychological Review, 74 (3), 183-200.

Block, Lauren G., Vicki G. Morwitz, William P. Putsis Jr., and Subrata K. Sen (2002), "Assessing the Impact of Antidrug Advertising on Adolescent Drug Consumption: Results from a Behavioral Economic Model," American Journal of Public Health, 92 (8), 1346-51.

Brown, Steven P. and Douglas M. Stayman (1992), "Antecedents and Consequences of Attitude Toward the Ad: A MetaAnalysis," Journal of Consumer Research, 19 (June), 34-51.

Bryant, Alison L., John Schulenberg, Jerald G. Bachman, Patrick O'Malley, and Lloyd P. Johnston (2002), "Understanding the Links Among School Misbehavior, Academic Achievement, and Cigarette Use: A National Panel of Adolescents," Prevention Science, 1 (June), 71-87.

Burke, Marian and Julie Edell (1989), "The Impact of Feelings on Ad-Based Affect and Cognition," Journal of Marketing Research, 26 (February), 69-83.

Campaign for Tobacco-Free Kids (2002), "State Initiatives," (July 3), [available at http://tobaccofreekids.org/campaign/state].

CDC (1999), Best Practices for Comprehensive Tobacco Control Programs-August 1999. Atlanta: CDC, 1-87.

- (2002), "Tobacco Information and Prevention Source," (July 15), (accessed March 5, 2004), [available at http:// www.cdc.gov/tobacco/issue.htm].

Chaloupka, Frank J., K.M. Cummings, C.P. Morley, and J.K. Horan (2002), "Tax, Price, and Cigarette Smoking: Evidence from the Tobacco Documents and Implications for Tobacco Company Marketing Strategies," Tobacco Control, 11 (Supplement I), i62-i72.
Chassin, Laurie, Clark C. Presson, Steven J. Sherman, Eric Corty, and Richard W. Olshavsky (1981), "Self Images and Cigarette Smoking in Adolescence," Personality and Social Psychology Bulletin, 7 (December), 670-76.

Cohen, Jacob and Patricia Cohen (1983), Applied Multiple Regression/Correlation Analysis for the Behavioral Sciences. Hillsdale, NJ: Lawrence Erlbaum Associates.

Cohen, Joel (2000), "Playing to Win: Marketing and Public Policy at Odds Over 'Joe Camel,"' Journal of Public Policy \& Marketing, 19 (Fall), 155-67.

Fishbein, Martin J. and Icek Ajzen (1975), Belief, Attitude, Intention, and Behavior: An Introduction to Theory and Research. Reading, MA: Addison-Wesley.

Fornell, Claes and David F. Larcker (1981), "Evaluating Structural Equation Models with Unobservable Variables and Measurement Error,' Journal of Marketing Research, 18 (February), $39-50$.

Friestad, Marion and Peter Wright (1994), "The Persuasion Knowledge Model: How People Cope with Persuasion Attempts," Journal of Consumer Research, 21 (June), 1-31.

Holmbeck, Grayson N. (1997), "Toward Terminological, Conceptual, and Statistical Clarity in the Study of Mediators and Moderators: Examples from the Child-Clinical and Pediatric Psychology Literatures," Journal of Consulting and Clinical Psychology, 65 (4), 599-610.

$\mathrm{Hu}$, Li-tze and Peter M. Bentler (1999), "Cutoff Criteria for Fit Indices in Covariance Structure Analysis: Conventional Criteria Versus New Alternatives," Structural Equation Modeling, 6 (1), 1-56.

Jamieson, Patrick and Daniel Romer (2001), "A Profile of Smokers and Smoking," in Smoking: Risk, Perception, \& Policy, Paul Slovic, ed. Thousand Oaks, CA: Sage Publications, 29-47.

John, Deborah Roedder (1999), "Consumer Socialization of Children: A Retrospective Look at Twenty-Five Years of Research," Journal of Consumer Research, 26 (December), 183-213.

Jöreskog, Karl G. and Dag Sörbom (1982), "Recent Developments in Structural Equation Modeling," Journal of Marketing Research, 19 (November), 404-416.

Kahneman, Daniel and Amos Tversky (1979), "Prospect Theory: An Analysis of Decisions Under Risk," Econometrica, 47 (March), 263-91.

Kaufman, Nancy J., Brian C. Castrucci, Paul D. Mowery, Karen K. Gerlach, Seth Emont, and C. Tracy Orleans (2002), "Predictors of Change on the Smoking Uptake Continuum Among Adolescents," Archives of Pediatric and Adolescent Medicine, 156 (6), 581-87.

Kenny, David A., Deborah A. Kashay, and Niall Bolger (1998), "Data Analysis in Social Psychology," in Handbook of Social Psychology, Vol. 1, 4th ed., D. Gilbert, S.T. Fiske, and G. Lindzey, eds. New York: McGraw-Hill, 233-65.

Lutz, Richard J. (1985), "Affective and Cognitive Antecedents of Attitude Toward the Ad: A Conceptual Framework," in Psychological Processes and Advertising Effects, Linda F. Alwitt and Andrew A. Mitchell, eds. Hillsdale, NJ: Lawrence Erlbaum Associates, 45-63.

Netemeyer, Richard G., James S. Boles, Daryl O. McKee, and Robert McMurrian (1997), "An Investigation into the Antecedents of Organizational Citizenship Behaviors in a Personnel Selling Context," Journal of Marketing, 61 (July), $85-98$.

Pechmann, Cornelia (1997), "Does Antismoking Advertising Combat Underage Smoking? A Review of Past Practices and Research," in Social Marketing: Theoretical and Practical Perspectives, Marvin E. Goldberg, Martin Fishbein, and Susan E. Middlestadt, eds. Mahwah, NJ: Lawrence Erlbaum Associates, 189-216. 
and Susan J. Knight (2002), "An Experimental Investigation of the Joint Effects of Advertising and Peers on Adolescents' Beliefs and Intentions About Cigarette Consumption," Journal of Consumer Research, 29 (June), 5-19.

_ and S. Ratneshwar (1994), "The Effects of Antismoking and Cigarette Advertising on Young Adolescents' Perceptions of Peers Who Smoke," Journal of Consumer Research, 21 (September), 236-51.

and Ellen Thomas Reibling (2000), "Planning an Effective Anti-Smoking Mass Media Campaign Targeting Adolescents," Journal of Public Health Management Practice, 6 (3), 80-94.

, Guangzhi Zhao, Marvin E. Goldberg, and Ellen Thomas Reibling (2003), "What to Convey in Antismoking Advertisements for Adolescents: The Use of Protection Motivation Theory to Identify Effective Message Themes," Journal of Marketing, 67 (April), 1-18.

Peracchio, Laura and David Luna (1998), "The Development of an Advertising Campaign to Discourage Smoking Initiation Among Children and Youth," Journal of Advertising, 27 (3), 49-56.

Petty, Richard E. and John T. Cacioppo (1981), Attitudes and Persuasion: Classic and Contemporary Approaches. Dubuque, IA: William C. Brown.

and (1986), Communication and Persuasion: Central and Peripheral Routes to Attitude Change. New York: Springer-Verlag.

Pollay, Richard W. and Anne M. Lavack (1993), "The Targeting of Youths by Cigarette Marketers: Archival Evidence on Trial," in Advances in Consumer Research, Vol. 20, Leigh McAllister and Michael L. Rothschild, eds. Provo, UT: Association for Consumer Research, 266-71.

$\longrightarrow$ S. Siddarth, Michael Siegel, Anne Haddix, Robert K. Merritt, Gary A. Giovino, and Michael P. Eriksen (1996), "The Last Straw? Cigarette Advertising and Realized Market Shares Among Youths and Adults, 1979-1993," Journal of Marketing, 60 (April), 1-16.

Popham, W. James, Linda K. Muthen, Lance D. Potter, Jacquolyn M. Duerr, Molly A. Hetrick, and Michael D. Johnson (1994), "Effectiveness of the California 1990-1991 Tobacco Education Media Campaign," American Journal of Preventive Medicine, 10 (6), 319-26.

Rindfleisch, Aric and David Crockett (1999), "Cigarette Smoking and Perceived Risk: A Multidimensional Investigation," Journal of Public Policy \& Marketing, 18 (Fall), 159-71.

Romer, Daniel and Patrick Jamieson (2001), "Advertising, Smoker Imagery, and the Diffusion of Smoking Behavior," in Smoking: Risk, Perception, \& Policy, Paul Slovic, ed. Thousand Oaks, CA: Sage Publications, 127-55.

Rose, Randall L., William O. Bearden, and Kenneth C. Manning (1996), 'Using Individual Differences to Segment the 'Market' for an Attribution-Based Substance Abuse Intervention Pro- gram," Journal of Public Policy \& Marketing, 15 (Fall), 252-62.

Schar, Elizabeth H. and Karen K. Gutierrez (2001), Smoking Cessation Media Campaigns from Around the World: Recommendations from Lessons Learned. Copenhagen: World Health Organization Regional Office for Europe, 1-35.

Schwarz, Norbert (1990), "Feelings as Information: Informational and Motivational Functions of Affective States," in Handbook of Motivation and Cognition, Vol. 2, E.T. Higgins and R.M. Sorrentino, eds. New York: Guilford, 527-61.

Sheppard, Blair H., Jon Hartwick, and Paul R. Warshaw (1988), "The Theory of Reasoned Action: A Meta-Analysis of Past Research with Recommendations for Modifications and Future Research," Journal of Consumer Research, 15 (December), 325-43.

Siegel, Michael and Lois Biener (2000), "The Impact of an Antismoking Media Campaign on Progression to Established Smoking: Results of a Longitudinal Youth Study," American Journal of Public Health, 90 (3), 380-86.

Simons-Morton, Bruce (2002), "Prospective Analysis of Peer and Parent Influences on Smoking Initiation Among Early Adolescents," Prevention Science, 3 (December), 275-83.

, Denise L. Haynie, Aria D. Crump, Patricia Eitel, and Keith E. Saylor (2001), "Peer and Parent Influences on Smoking and Drinking Among Early Adolescents," Health Education \& Behavior, 28 (1), 95-107.

Slovic, Paul (2001), "Cigarette Smokers: Rational Actors or Rational Fools?" in Smoking: Risk, Perception, \& Policy, Paul Slovic, ed. Thousand Oaks, CA: Sage Publications, 97-124.

___ Baruch Fischhoff, and Sarah Lichtenstein (1980), "Informing People about Risk," in Banbury Report 6: Product Labeling and Health Risks, Louis A. Morris, Michael B. Mazis, and Ivan Barofsky, eds. Cold Spring Harbor, NY: Cold Spring Harbor Laboratory, 165-81.

Smith, Karen H. and Mary Ann Stutts (1999), "Factors That Influence Adolescents to Smoke," Journal of Consumer Affairs, 33 (2), 321-57.

Smith, Robert E. and William E. Swinyard (1982), "Information Response Models: An Integrated Approach," Journal of Marketing, 46 (Winter), 81-93.

Stacy, Alan W., Peter M. Bentler, and Brian R. Flay (1994), "Attitudes and Health Behavior in Diverse Populations: Alcohol Use, Binge Eating, Marijuana Use, and Cigarette Use," Health Psychology, 13 (1), 73-85.

Vakratsas, Demetrios and Tim Ambler (1999), "How Advertising Works: What Do We Really Know?" Journal of Marketing, 63 (January), 26-43.

WTCB (2000), "Strategic Plan Brief," (October 1), 1-6.

(2002), "Statutory Charge: Summary of Legislative Authorization and Allowable Tobacco Control Board Activities," (July 25), 1-2. 